\title{
A New Approach to Assess the Normalization of Differential Rates of Protest Participation
}

\section{Clare Saunders and Natalie Shlomo}

Pre-proofs version, accepted for publication in Quality and Quantity, 9 May 2020

\begin{abstract}
Research that compares those who do and do not participate in protest over time purports that protesters are becoming increasingly similar to the non-protesting population. Using a protest survey that includes the frequency of protest participation, we consider the extent to which those who protest to different degrees are similar to non-protesters. Selection bias in nonprobability protest survey data is compensated for by combining the data with random reference samples from the European Social Survey under a quasi-randomisation approach. We test hypotheses on the normalization of protesters and compare two methods for compensating for selection bias: a proportional weighting method and a propensity score adjustment method. The propensity score adjustment method is more effective in mitigating selection bias by balancing on variables that explain the selection and outcome, and enables the comparison of groups of protesters to non-protesters. We find that protesters become increasingly differentiated from non-protesters as their extent of protest participation increases according to their left-wing self-placement and education.
\end{abstract}

Key words: normalization of protest, political participation, protest inequalities, protest survey, propensity score adjustment 


\section{A New Approach to Assess the Normalization of Differential Rates of Protest Participation}

\section{Introduction}

Protest is no longer considered a minority activity undertaken by extreme radicals, but rather it is viewed as an important way for citizens to signal their political discontentment (refer to Norris 2003; Walgrave et al 2016). As protest has routinized, the characteristics of protesters and the general public are thought to have converged (Van Aelst and Walgrave 2001). There are two main approaches to understanding the types of people who participate in protest, which this paper combines in a novel way. The first body of research, which we call the binary approach, compares those who protest to those who do not. The binary approach draws on surveys with random samples (often in cross-national perspective), like the European Social Survey (ESS) or World Values Survey (WVS). It facilitates comparisons of those who protest with those who do not, based only on survey questions with a 'yes/no' response. The second approach compares only sub-groups of protesters without a control group of non-protesters to whom they can be compared. Therefore it could be said to lack a control group and/or of selection on the dependent variable. We call this the lack of control group approach. Such data comes from protest surveys (Klandermans et al 2009) that, despite state-of-the-art methodology, continue to face issues with selection bias, i.e. not all protesters have a chance of being selected to the sample, due to the impossibility of achieving a representative sample of protest attendees (Walgrave et al 2016).

The different sampling strategies have made it hitherto impossible to compare sub-groups of protesters (available from non-probability protest surveys which suffer from selection bias) to non-protesters (available from the binary approach in random surveys such as the ESS). In this paper, we illustrate a methodology that allows us to compensate for selection bias in the 
non-probability sample using a quasi-randomization approach that integrates the nonprobability sample with a probability sample of protesters from the ESS. The result is a substantive and methodological contribution to the literature. Substantively we compare those who protest with different degrees of frequency to those who do not protest at all.

Methodologically, we illustrate the utility of a propensity score stratification adjustment with benchmarking to compensate for selection bias in the non-probability sample of protesters. We are then able to combine the data on non-protesters from the ESS with the data of protesters which includes the different sub-group classifications of protesters. This allows us to bring nuance to the binary approach by including a control group to the protest survey data. This methodology, we argue, is useful beyond the application we make herein: it can be easily adapted to other on-site studies with rare populations or surveys collected over the internet, which face similar problems related to selection bias and non-probability sampling.

Our paper has the following objectives:

- A critical review of existing literature on the normalization of protest, which establishes the case we make for our re-assessment of the normalization of the protester thesis.

- An appraisal of existing protest survey data methodology, which faces barriers to achieving a probability sample. This allows us to make the case for the need to compensate for selection bias in a non-probability sample.

- An evaluation of two quasi-randomisation approaches - a proportional weighting method and a propensity score adjustment method - for integrating data from the binary approach with protest survey data. 
- Statistical analysis that allows us to understand which sub-groups of protesters based on their frequency of protest - are the most 'normal', through a comparison with non-protesters.

\section{Literature review}

\subsection{Comparing protesters to non-protesters: the binary approach}

The first quantitative study of political participation in Britain was Barnes and Kaase's (1979) seminal Political Action. They concluded that the types of protest actions that were deemed radical in the 1960s were becoming assimilated into the political repertoire of average citizens, in other words they were becoming normalized. However, there were still some protest inequalities: those with 'high protest potential' were younger, more likely to be male and were more highly educated. Younger women were equally attracted to protest as young men, even though they shunned unlawful forms of protest, but older women were more sceptical (refer to Dalton 1996, Marsh 1990).

Pattie et al (2004) surveyed 1,600 people in Britain, finding that, in 1986, 6\% of the British population had 'taken part in a protest march or demonstration'. Protesters were disproportionately men, but the effect of gender on participation was marginal once barriers to women's participation were taken into account. The study found that young people (aged 18-29) had a slight participation deficit in 'collective action', but were more likely to engage in direct action. By 2002, only $4 \%$ of British people had 'taken part in a protest march or demonstration' (Whiteley 2011). 
Gallego (2008) analysed 2004 ESS data on 22 European countries (including Britain) and found - in line with other studies - that men were more likely to attend demonstrations than women, but the effect was small when other variables were controlled for. Young people demonstrated more, as did the more highly educated. Income, social class, ethnic minority and citizen status had no statistical significance. According to Gallego (2008:21) 'this finding can be interpreted as giving some support to the "normalization" hypothesis'.

Contra to assertions of normalization, Dalton (2018) found a modestly increasing education gap among protesters 1975-2014 in the UK. This appeared to suggest that higher levels of education were now marginally more likely to predict participation in a demonstration. However, it is worth considering that the 1975 data asked respondents whether they had attended a lawful demonstration in the past 10 years, whereas the 2014 data asked whether they had 'took (sic) part' in a demonstration in the past year. A wider pool of individuals will have attended a demonstration in the past 10 years (by virtue of the time period asked about in the question) compared to the past year which perhaps illustrates that the alleged trend is an artefact of the data. Dalton (2017: 180) himself warns 'Readers beware. On close inspection ... inconsistencies in methodology or basic question wording make comparisons [over time] tenuous'.

The lack of reliable longitudinal data on the characteristics of protesters (Rucht 2007) exists for two reasons. The first, alluded to above, relates to question wording. There are multiple variants of questions asked, in addition to those used by Dalton (2017), for example: 'would you' engage in protest (known as protest potential, refer to Barnes and Kaase 1979), 'the past 5 years or so' (Comparative Electoral Studies, refer to Dalton 1996); and 'ever' (World Values Survey, refer to Rucht 2007). Dalton (2017) is not the only scholar to make invalid comparisons over time due to analysing responses to different variants of questions. Pattie et 
al (2004), for example, admit that their comparisons overtime depend on the extent to which question wordings allow for meaningful comparisons, casting doubt on trends they purport to show. The second reason to question the reliability of longitudinal data on protest inequalities relates to the different ways in which protest is operationalized. Some scholars lump together different forms of protest. Vráblíková (2014), for example, combines signing a petition, taking part in a demonstration and attending a political meeting with other indicators of non-electoral participation, whereas others single out specific repertories such as street demonstrations (Saunders 2014) or strikes (Biggs 2015). Despite its many weaknesses, such data is oftentimes used to affirm notions that we live in a 'demonstration democracy' (Etzoni 1970) or a 'social movement society' (Meyer and Tarrow 1988). As we have illustrated, the specific evidence from published studies is less clear about the extent to which protest is normalized than these proclamations, suggesting the need for our reappraisal of evidence.

\subsection{Evidence from protest surveys: lack of a control group approach}

Protest survey research switches the emphasis from normalization of protest per se to normalization of the protester. A seminal study in this field is by Van Aelst and Walgrave (2001), who find, not unreservedly, that there is some evidence of the normalization of the protester. Protesters, they argue, are highly educated and tend not to be among vulnerable or needy groups in society. Despite this, they argue that there has been 'a social diffusion of protest' (ibid, p.481). However, their study does not consider similarities and differences between protesters and the general public, making it difficult for them to make firm conclusions about the extent to which protesters are normalized. Saunders (2014) has made comparisons across protesters and non-protesters using 2012 ESS data, and, in the same paper also looked at differences among novice, returner, repeater and stalwart protesters 
using protest survey data. However, analyzing these two datasets separately did not allow a direct comparison between sub-groups of protesters with non-protesters.

\subsection{A new approach to reassessing the normalization of the protester thesis}

We combine data from the binary approach with that from the more nuanced protest survey approach in order to capitalise on the relative advantages and minimise the disadvantages of each. Similar to Van Aelst and Walgrave (2001), we are not looking at trends for the normalization of protest, but rather for the normalization of the protester. We analyse the extent to which those who protest to differential degrees are normalized in the combined years 2009-2013. This is an important time period to study because it witnessed the rise of an anti-austerity cycle of contention (Bailey 2013). Methodologically, we illustrate the use of a propensity score stratification adjustment with benchmarking to integrate the non-probability sample of protesters derived from the Caught in the Act of Protest Contextualising Contestation project (CCC) with the random sample of UK ESS, and compare this to a standard approach based on benchmarking alone.

Given that over $96 \%$ of the UK population are non-protesters, according to the findings of the UK ESS (2008-2013 combined), we make the assumption that their characteristics will not differ from the general population. In contrast, protesters, defined here as participants in street demonstrations, are a small minority of the population $(3.8 \%$ according to the UK ESS for our period of study). We therefore can assess the extent to which different sub-groups of protesters have become normalized on the basis of a comparison of non-protesters to protesters. 
We proceed as follows. In Section 3, we present our hypotheses. We introduce the data and methodology in Section 4. First, we describe the CCC sampling protocols that seek to distribute questionnaires to a representative sample of protesters and make it possible to estimate response bias (Van Stekelenberg et al 2012). Despite very commendable protocols and the best efforts of the research team, there remains selection and response bias (Walgrave et al 2016). Second, we describe different approaches to compensate for selection bias in the non-probability CCC sample and focus on two quasi-randomisation methods to integrate the CCC protesters into the ESS sample: (1) proportional weighting with population benchmarking (from here on, proportional weighting); and (2) propensity score stratification also with population benchmarking (from here on, propensity score adjustment).

We then describe the dependent and independent variables in our model of interest. In Section 5, we present our findings which first address the fit of samples derived from proportional weighting and propensity score adjustment by comparing the frequencies of key variables of interest with the complete ESS data-file (consisting of protesters and nonprotesters). We also assess our two samples by comparing the characteristics of ESS protesters to the raw $\mathrm{CCC}$ data (which already consists of protesters only). In Section 6 we present our discussion and conclusions and address our substantive and methodological contributions. We close in Section 7 with future studies and limitations. Figure 1 shows a schematic diagram that explains the analytical strategy of this study.

<Insert Figure 1 here>

\section{Hypotheses}


As we explained above, existing literature suggests that normalization of the protester is underway, but incomplete. There are two ways to infer hypotheses from this. The first is to view the 'normality' of protesters as a matter of degree: those who protest the least are the most similar to the general public (Saunders et al 2012). The second is to view it as a matter of non-monotonic differentiation, viewing those who protest the most and novices as less special or different (more on this, below). Should we take the first approach, we would hypothesize:

H1: Under the period examined, novices are the most normalized, stalwarts are the least normalized and middle-group fall between the two extremes.

Taking a contrasting non-monotonic approach, we might expect that the middle-group are the most normal. This is because they are by far the largest sub-group (Saunders et al 2012) and are, at least theoretically, the least remarkable. In our dataset (described in Section 4), there are 2,002 protesters in the middle group compared to only 182 novices (first-time protesters) and 349 stalwarts. Novices face high barriers to first-time protest participation (Verlhulst and Walgrave 2009). Consensus mobilization, which involves agreeing with the aims of a demonstration, is relatively easy. In contrast, action mobilization, which involves actually attending a demonstration, is a much more difficult step, requiring considerably more commitment and dedication. Researchers have long established that, in practice, a large majority of movement sympathizers fail to make it along to a protest (Klandermans and Oegema 1987). This implies that there is something special about novices. Additionally, evidence from a Dutch survey of protesters finds that novices tend to be younger (Verlhulst and Walgrave 2009).

By contrast, stalwarts can legitimately be thought of as highly committed protesters who require special life circumstances to sustain their involvement (Downton and Wehr 1998). 
Persistent activists are known to be different in a variety of ways from those who withdraw from activism. They tend not to have married spouses or children (CorrigallBrown 2012) and are more likely to be male. They are better socialized into networks of activists and organizations (McAdam and Paulsen 1993; McAdam 1986; Oberschall 1973; Snow 2010), including in their friendship and familial networks (Stryker 1968) and are more likely to use of protest vis-à-vis other forms of political participation (Dalton 2002). In their study of novices, returners, repeaters and stalwarts, Saunders et al (2012) found that the stalwarts were much more left-wing than novices and the middle-group (which is co-constituted of their "returners" and "repeaters"). We might, for these reasons combined, realistically posit that those in between the two extremes of protests (i.e, the middle-group) are the least exceptional. Thus, our second and contrasting hypothesis, which draws on Verhulst and Walgrave (2009) is:

H2. Under the period examined, the middle-group are the most normalized. Novices and stalwarts have the most distinct characteristics compared to non-protesters.

\section{Data and Methods}

\subsection{CCC dataset}

The CCC project collected survey responses at 13 randomly selected demonstrations in London during the years 2009-2013 (Table 1). Although the demonstrations took place in London, protesters travelled from multiple cities across the UK to attend them.

$<$ Table 1 here>

The CCC methodology involves preparing 1,000 postal survey questionnaire booklets accompanied with pre-addressed stamped envelopes, and handing them out systematically at 
demonstrations. In the UK sample, postal survey response rates varied across demonstrations from around $9 \%$ to $35 \%$ (Walgrave et al 2016). Aware of refusal bias from earlier protest surveying attempts, the CCC team devised a method to test its extent. One in every five questionnaire booklets is accompanied by short matched-numbered face-to-face interview. Those receiving interviews and/or questionnaire booklets are randomly selected by a team leader in every nth row, depending on demonstration size. Those who are interviewed and who return a face-to-face survey are considered representative of those who respond to the survey. Given that face-to-face interview refusal rates are low, those answering only the faceto-face survey approximate a random and representative sample of those who accept but do not return a questionnaire. Comparing these two sub-samples allows for an approximation of response bias (Van de Stekelenberg et al 2012).

The CCC project sampling methodology represents the state-of-the-art in protest surveying. However, Walgrave et al.'s (2016) analysis of selection and response bias in the CCC data on 51 demonstrations across Europe finds (among other things) that around one-fifth of surveyed demonstrations were too chaotic to effectively sample randomly. Over half of the time, the field supervisor wrongly estimated the demonstration size, which meant that the one-inevery-n rows randomisation technique did not always ensure that everyone on the protest had a random chance of selection. In four of every five demonstrations, fieldwork interviewers reported losing their 'pointer'. In such a situation, they were instructed to continue alone, potentially leading to selection bias. The refusal rate for face-to-face interviews was substantially higher than in field trials (at 13\%) making it more difficult to accurately measure and account for response bias than anticipated. Overall, it is known that respondents to the mail back survey are more likely to be female, that they are more interested in politics and are better educated compared to interview-only respondents (Walgrave et al 2016). 
In addition to selection and response bias, there is also bias in the selection of demonstrations surveyed. For feasibility, the protest survey technique requires that the research team attend only demonstrations anticipated to attract over 2,000 people so that the survey team do not become overly conspicuous. Moreover, all demonstrations must be relatively 'safe' for a research team to avoid breaching research ethics agreements or jeopardising fieldworkers' safety. To be noticed by the research team, in the first instance, protests also needed to be well advertised. They must also be advertised in advance because researchers require time to prepare the necessary paperwork and brief field workers. This resulted in an over-sampling of left-wing demonstrations that tend to be larger and less violent.

The final UK CCC dataset had 2,533 records after deleting 29 records with missing values in the covariates of our substantive model. There were initially 303 missing values in the dependent variable that measures frequency and intensity of protest participation (novice, stalwart and middle-group, see definitions below). These were imputed by nearest neighbour hot-deck imputation where the imputation classes were composed of gender, age, having a university degree, wearing a badge, signing a petition, and boycotting products (see Table A1 of the Appendix for variable descriptions).

\subsection{ESS dataset}

In addition to the UK CCC dataset (2009-13) we used the UK ESS dataset 2008, 2010, 2012 and 2014 combined. These years approximate the period in which demonstrations were sampled for CCC (2009-2013) and allowed for more power to test hypotheses. We note here that there were no differences in attributes over the samples of the UK ESS for the protesters 
and non-protesters and the sample sizes were stable over the years. The appropriate design weights for each sample were used in the analysis.

The UK ESS is a representative survey of all persons resident within private households in the UK aged 15 and over. ESS uses a clustered, stratified, 3-stage random probability sample design with unequal probabilities of selection within the household, i.e. one adult was sampled in each selected household. Given unequal probabilities of selection, the provided design weights are used in all analysis of ESS data. The final UK ESS dataset had 9,222 individuals after deleting 51 individuals due to missing values for some of the covariates of our substantive model. One of the questions in the ESS survey is: 'Have you participated in a legal public demonstration in the past 12 months?'. This question is used to differentiate protesters from non-protesters. There were 351 protesters and 8,871 non-protesters in the combined UK ESS dataset.

\subsection{Final Combined Dataset}

To prepare the dataset for substantive analysis, we compensate for the selection bias in the CCC dataset by integrating it with the random sample of the ESS protesters (those who said "yes" to having participated in a demonstration in the past 12 months). We take into account the ESS survey design by using design weights. An overview of methods to compensate for non-probability samples is provided by Baker et al (2013) and more recently by Elliot and Valliant (2017). Under the quasi-randomisation setting, the two main approaches are sample matching and post-hoc adjustments using auxiliary data, for example through propensity score adjustment. Both require the use of a reference sample. Other approaches in the literature use model-based estimation techniques which we do not consider in this paper. 
Sample matching has been used in comparative studies to reduce bias in computing estimates of differences between a treatment and a control group. In non-probability samples, we match units in the non-probability sample to a reference sample based on a set of control variables that explain both the participation and the outcome so that the covariates are balanced (Rivers and Bailey 2009). Then, inference is carried out using the survey weights of the reference sample. Under this method, however, we lose data for many protesters in the CCC sample since the sample size is 2,533 compared to only 351 protesters in the ESS. We therefore implement another quasi-randomisation method based on a propensity score adjustment (Lee and Valliant 2009) that allows us to utilize all of the protesters in the CCC dataset. In this approach, we stack the non-probability sample and the reference sample and estimate the probability of participation in the non-probability sample using a logistic regression model where control variables explain both the participation and outcome variables. We then use the predicted probabilities in the calculation of weights for the non-probability sample. This is followed by post-stratification, which benchmarks to known population totals to further reduce the impact of selection bias as well as compensate for the response bias identified in the CCC dataset. To compare the propensity score adjustment method, we also consider just the post-stratification step after a proportional adjustment based on the number of protesters versus non-protesters as found in the ESS.

Whilst the second method of using just the post-stratification step to adjust non-probability samples may be more common in practice when random probability samples may not be available as reference samples, we expect that the propensity score adjustment method will perform better. The propensity score adjustment method explicitly accounts for the selection bias by combining with a random reference sample having relevant overlapping covariates 
(Elliot 2009; Elliot and Valliant 2017). We describe next the two methods used in this study in more detail.

\section{Proportional weighting}

The ESS protesters are replaced with protesters obtained from the CCC dataset. We set the design weight $d_{i}^{*}=1$ for individual $i$ in the CCC dataset whilst retaining the original design weights of the ESS for the non-protesters: $d_{i}^{*}=d_{i}^{\text {orig }}$. An initial correction factor $C$ is applied to the design weights $d_{i}^{*}$ to correct for the proportion of protesters in the new dataset to be equal to the proportion estimated from the original ESS dataset. The average proportion of protesters across the four waves in the original (survey weighted and cleaned) ESS dataset was $3.8 \%$. In the final step, we use post-stratification benchmarking to adjust the new design weights $C d_{i}^{*}$ for individual $i$ based on the UK Census 2011 population distribution of age group x sex. The final weights are calculated as follows: $w_{h i}^{*}=\left[N_{h} / \sum_{i \in h} C d_{i}^{*}\right] \times C d_{i}^{*}$ where $N_{h}$ is the size of the post-stratum group $h$. Final weights are normalised to the sample size for convenience $(\mathrm{n}=11,404)$.

\section{Propensity Score Adjustment}

We modify the propensity score adjustment approach from the matched sampling approach in quasi-experimental or observational designs (Holmes 2014). In these types of research designs, groups are adjusted, matched, stratified or weighted where randomness cannot be guaranteed, so that differences on confounding variables are minimised or eliminated and the samples are more balanced (Rubin 1979). 
Step 1: The CCC dataset is added to the ESS protesters. Let $R_{i}=1$ if $i$ in ESS, otherwise $R_{i}=0$. Using a logistic regression model, we estimate:

$$
\operatorname{Pr}(E S S=1)=\frac{e^{\mathbf{\beta} \mathbf{x}}}{1+e^{\mathbf{\beta x}}}=p_{i}
$$

where the covariates are those in our substantive model (see Table 4 ) in addition to other known predictors of protest participation such as voting in an election, wearing a badge, signing a petition, contacting a politician and boycotting products.

Step 2: Based on the sub-group of ESS protesters only, we sort their estimated propensities $\hat{p}_{i}$ and divide the ESS protesters into quintiles for determining cut-off thresholds $\hat{p}_{i}^{q}$. In each quintile $q$, we aggregate the original ESS design weights: $\sum_{i \in q} d_{i}^{\text {orig }}$.

Cochran (1968) showed that $90 \%$ of the differences between control and treatment groups in quasi-experimental studies could be reduced by stratifying on five groups. Rosenbaum and Rubin (1984) estimated that the figure was as high as 95\%. Sample adjustments are made within the resulting five stratification groups as opposed to a direct linkage, protecting against possible misspecification of the model.

Step 3: Turning to the CCC dataset, we define the five stratification groups according to the same $\hat{p}_{i}^{q}$ from Step 2. Each protester $i$ in strata $q$ in the CCC dataset is given a design weight as follows:

$$
d_{i}^{* q}=\left[\sum_{i \in q} d_{i}^{\text {orig }} / n_{c c c}^{q}\right]
$$

where the numerator is the sum of the original $d_{i}^{\text {orig }}$ from the ESS protesters in strata $q$ as calculated in Step 2 and the denominator $n_{c c c}^{q}$ is the number of CCC protesters in strata $q$. 
Step 4: Next, we combine CCC protesters having design weights $d_{i}^{* q}$ from Step 3 with the ESS non-protesters where $d_{i}^{*}=d_{i}^{\text {orig }}$ refers to their original design weights. Dropping the index for $q$, the resulting design weights for the combined dataset are then post-stratified according to the UK Census 2011 population distribution of age group $\mathrm{x}$ sex. The final weight for individual $i$ is calculated as follows: $w_{h i}^{*}=\left[N_{h} / \sum_{i \in h} d_{i}^{*}\right] \times d_{i}^{*}$ where $N_{h}$ is the size of the post-stratum group $h$. Similar to the proportional weighting method, final weights are normalised to the sample size for convenience.

\subsection{Dependent and independent variables}

The dependent variable modifies Saunders et al's (2012) classification of protesters by adding non-protesters and aggregating returners and repeaters. The resultant dependent variable is coded as follows:

$0=$ Non-protester: has not participated in a protest in the past 12 months (ESS). $1=$ Novice $:$ surveyed at their first protest ever (CCC).

2=Middle-group: more than 1 previous demonstration in the past 12 months, but less than 6 ever (CCC).

$3=$ Stalwarts: more than 6 demonstrations in the past 12 months, and more than 6 ever (CCC).

Following the literature on inequalities in protest participation introduced above, the independent variables are age, education and gender. We also add self-placement on the leftright scale (recoded into an ordinal variable, with zero for 'don't know' as a separate category) because many protests (especially those in the CCC dataset) are on issues usually associated with left wing politics. We add the additional control of political interest, which is 
known to be a strong predictor of political participation. It is important to point out that the demonstrations in the CCC dataset were on issues usually associated with left-wing politics (refer to Torcal et al 2016), but that the propensity score adjustment method compensates for protesters' left-wing bias. See Table A1 of the Appendix for detail of the coding of independent and auxiliary variables.

For the modelling we use the svy command in STATA to analyse the data with the survey weights in order to obtain proper variance estimates for inference. Besides the survey weights, there were no other design variables in the analysis. We then use the multinomial logistic regression command (mlogit) in STATA.

\section{$5 \quad$ Findings}

\subsection{Representativeness of the data under the quasi-randomisation approach}

In the first set of findings (Table 2 and Table 3) we assess the representativeness of the data under the quasi-randomisation approach for the two methods of proportional weighting and the propensity score adjustment. In Table 2 we compare the frequencies of key variables that explain both the outcome variable and participation in the CCC sample. A similar estimate across the methods is indicative that the integration of the CCC protesters into the ESS dataset provides a reasonable compensation approach for the non-probability CCC sample. The proportional weighting method increases the percentage of protesters slightly compared to the original UK ESS dataset but all of the variables have similar frequencies across the two adjustment methods and none of the differences are statistically significant demonstrating that the key variables are balanced in the original and combined surveys.

<Table 2 here> 
In Table 3, we present a comparison of the protesters only in the original UK ESS with the CCC protesters after the sample adjustment methods. We have also included the column entitled 'CCC (raw)' to illustrate how the propensity score adjustment method provides a closer fit to the UK ESS sample of protesters compared to the original (raw) CCC sample. It is particularly noteworthy that the CCC respondents are very highly educated $(82.5 \%$ claimed to have a degree). The propensity score adjustment method corrects this, reducing it to $38.1 \%$, which is more comparable to the UK ESS protesters $(35.7 \%)$. This adjustment is reasonable since there is a known response bias in the CCC data in favour of the more highly educated (Walgrave et al. 2016). It also appears that there is a response bias against centrists and right-wing protesters, which have also been corrected by the propensity score adjustment approach. Table 3 illustrates that proportional weighting is a rather naïve approach, since the adjusted sample does not differ much from the CCC raw dataset. Moreover, under the propensity score adjustment method, there are no statistically significant differences between the UK ESS (with design weights) and the CCC on key variables.

$<$ Table 3 here>

In summary, Tables 2 and 3 show that the propensity score adjustment method balances the CCC non-probability sample on a set of covariates that explain both the outcome variable and participation in the CCC sample. This method makes it comparable to the ESS and enables statistical inference to test our hypotheses. We turn now to our substantive model of interest.

\subsection{The model of interest}

In Table 4 we present descriptive statistics comparing the distribution of the variables in our model of interest, across the four sub-groups (non-protesters, novices, the middle-group and 
stalwarts). We compare three samples: a) the raw unadjusted combined CCC and UK ESS dataset; b) the integrated dataset after applying the proportionally weighted adjustment method; and c) the integrated dataset after adjusting the sample using the propensity score adjustment method. The significant difference in gender across the four sub-samples (nonprotesters, novices, the middle-group and stalwarts) becomes non-significant in the sample under the propensity score adjustment, which substantially reduces the female bias in the UK ESS (this is likely an artefact of the ESS sampling strategy). Compared to the dataset under the proportional weighting method, the propensity score adjustment method makes large corrections for having a university degree. Once corrected, the 'has a degree' variable now has a monotonic increasing relationship with protester status. The highly educated appear disproportionately among the more frequent activists (the stalwarts) compared to novices and the middle-group. The mean age of non-protesters is most similar, in all samples, to the mean age of stalwarts. By all accounts, novices are younger and the middle-group are, on average, older than novices but younger than stalwarts. This might seem to be an artefact of the construction of the dependent variable, but in Saunders et al (2012) where different subgroups of protesters were studied and did not include 'non-protesters', 15\% of young people (aged 18-25) were classified as stalwarts, which is a higher percentage than for any other age group. Since $18.2 \%$ of the stalwarts in the sample are young (despite the relatively small numbers of young people in the sample), operationalization of the stalwart category does not unduly discriminate against young people.

Political interest also has a monotonic increasing relationship with protesters' status. However, the effect is slightly tempered using the propensity score adjustment approach. Only after the propensity score adjustment method do stalwarts appear slightly less politically interested than the middle-group. Thus, the propensity score adjustment method appears to 
correct the selection bias in the non-probability CCC data set and generally, the politically interested have a greater proclivity to respond.

Non-protesters and novices are the two sub-groups most likely to answer 'don't know' in response to a question about their location on the left-right scale. Non-protesters are markedly more likely to place themselves in the centre of the political scale, followed by novices. Whichever adjustment method is used, extreme left positions are most common among the stalwarts who also entirely avoid placing themselves at the extreme right of the scale. The propensity score adjustment method makes some adjustments on the left-right scale, which seems indicative of the under-sampling of right-wing demonstrators, which is hardly surprising given the left-wing nature of most of the demonstrations surveyed (Table 1). It is important to note, however, that the student demonstrations and the 'Take Back Parliament' demonstration were among the demonstrations to attract lower numbers of left-wing protesters compared to demonstrations on other issues.

<Table 4 here>

Table 5 presents the multinomial logistic regression results with the three variations of datasets as defined in Table 4. The raw unadjusted combined ESS and CCC dataset is included to allow the reader to make an interpretation of model fit under the pseudo- $\mathrm{R}^{2}$, whereas an adjusted F-corrected Wald Statistic is used for the analysis of the weighted datasets under the svy command of STATA. The regression model for the raw data is also included to make it possible to observe the way in which coefficients change as we make necessary adjustments to compensate for the non-probability CCC sample. It is important to note the relatively high pseudo- $\mathrm{R}^{2}$ score $(0.41)$ in the regression model on the raw data. This 
suggests that the predictor variables do a satisfactory job of predicting whether someone is a non-protester, a novice, in the middle group, or a stalwart.

Under the proportionally weighted dataset, we find novices are younger than non-protesters, more politically interested, less likely to be centrist or moderate right and more likely to have a degree. The middle-group are also younger, more politically interested and more highly educated than non-protesters. When it comes to left-right self-placement, they are more likely to be left-wing and less likely to be centrist or right-wing. Stalwarts are also younger, more highly educated and more politically interested than non-protesters. In addition, stalwarts are more likely to be male. Stalwarts are the most likely of all to place themselves at the extreme left of the left-right scale, and to not be centrist or right-wing. All of the protesters are less likely than the non-protesters to say that they 'don't know' their left-right self-placement. These results are not substantively different from the results of analysis on the raw combined file.

The multinomial regression results on the dataset under the propensity score adjustment method tell a slightly different story. Compared to non-protesters, novices are more likely to be extreme left and have a degree. The middle-group are more politically interested and tend to have a left-wing or centrist left-right self-placement. They, too, are better educated than novices. Stalwarts are the most likely to be extreme left, and if they are not extreme left, they tend to be moderate left. They are also significantly less likely to be extreme right. They are the most likely group to have a degree. Using this method, the model does not distinguish stalwarts from non-protesters with regards to age.

$<$ Table 5 here > 
Under the propensity score adjustment method, we now test whether protesters become increasingly differentiated from non-protesters as their extent of protest participation increases. Table A2 in the Appendix includes F-statistics and their significance level for testing differences in effect sizes between: novices and the middle group; the middle group and stalwarts; and novices and stalwarts. There are significant monotonic increasing effects for the extreme and moderate left placement and for having a university degree when moving from novices to stalwarts. Political interest and centrist placement have a significant increasing effect from novices to the middle group and the middle group to stalwarts, but there is no significant effect difference between novices and stalwarts. On the other hand, extreme right placement has a significant increasing effect from the middle group to stalwarts and novices to stalwarts, but no significant effect difference between novices and the middle group.

The final step in our analysis recognises the importance of specific grievances in mobilising people to participate on particular issues (van Stekelenburg and Klandermans 2013). The population of protesters in the CCC dataset may for this reason be demonstration context dependent. Some might warn against aggregating protesters who protested on different issues. The same concern could be levelled at analysis of ESS protesters, who are also aggregated without regard for the protest issue. To understand how the different sub-groups of protesters (novices, the middle group and stalwarts) are distributed across demonstrations, we ran our substantive model on protesters only, with novices as the reference category, and include demonstration as a fixed effect in Table A3 of the Appendix. The results on the raw data indicate that in comparison to those on the 'The Big If 2013' demonstration, protesters on 'Unite Against Fascism 2010', 'The Climate March 2010' and the '2 $2^{\text {nd }}$ National Student 
Demo 2010' were more likely to be in the middle group than to be novices. Stalwarts appear to be more prolific on these demonstrations as well, but they are also found more frequently on the 'Million Women Rise 2010', 'Occupy 2011', 'Take Back Parliament 2010' and 'May Day 2010 '. The model under the propensity score adjustment reduces many of the demonstration effects. This is not to suggest that context does not matter, but rather to show how our propensity score adjustment method reduces some of the more significant demonstration-specific differences in the proportions of protesters in the novice, the middle group and stalwart categories.

\section{Discussion and Conclusions}

The study had two key research aims. Substantively, we carried out statistical analyses to test which group of protesters, as defined by their extent of protest, have most comprehensively normalized by comparing them to non-protesters. Methodologically, we solved two problems inherent in protest surveying: these are non-probability sampling and sampling on the dependent variable. We solved these problems by combining the non-random CCC protest survey with the random UK ESS dataset of protesters using a propensity score stratification adjustment and benchmarking to known population totals. Thus, we were able to carry out a new analytical approach that went beyond the binary approach and brought the benefits of a control group to the protest survey data.

More specifically, instead of comparing non-protesters to a homogenous category of protesters, we defined sub-groups of protesters - namely, novices, the middle group and stalwarts. We posed two contrasting hypotheses under the period examined: Are protesters less like the general public as they participate in protest to a greater extent (H1)? Or, is the 
middle-group the most similar to the general public given the special characteristics required in order to be a novice or stalwart (H2)? We find more support for $\mathrm{H} 1$ than $\mathrm{H} 2$.

Using the proportionally weighted sample and propensity score adjustment datasets, novices appeared most similar to non-protesters. The analysis on data adjusted by the propensity score adjustment method in Table 5 showed that novices are significantly more likely to be extreme left than non-protesters, but the coefficient is markedly lower than for the middlegroup and stalwarts which are both significant (the coefficients are 0.99 for the novices, 1.46 for the middle-group and 2.92 for the stalwarts). They were also more likely to hold a degree compared to non-protesters, but the coefficient is only slightly lower than for the other two sub-samples of protesters (the coefficients are 0.76 for the novices, 0.78 for the middle-group and 1.20 for the stalwarts and are all significant). The findings in Table A2 of the Appendix show that there were significant monotonic increasing effect sizes across the groups for these variables. In addition, the sample adjusted by proportional weighting had very similar demonstration effects to the raw data, and these were reduced - but not eliminated - under the propensity score adjustment approach (Table A3).

The middle-group were more politically interested than novices, markedly more left-wing and better educated. Stalwarts were yet more markedly left-wing, apparently doggedly not right-wing and better educated still. This lends support to $\mathrm{H} 1$, which posited that: H1: Under the period examined, novices are the most normalized, stalwarts are the least normalized and middle-group fall between the two extremes.

This is an important finding in relation to the literature on the normalization of protest. If it is true that protesters are becoming increasingly like the general public over time, this is 
mitigated by the fact that those who protest for longer periods of time (i.e. the stalwarts) are the most distinct from the general public. This may go some way towards explaining enduring protest inequalities in relation to gender and education. It is also important to note that the largest group of protesters, found in the middle group, are not the most normalized, despite the size of their group and the challenges of stepping into protesting as a first-timer.

But which sample adjustment do we recommend? Our descriptive analysis in Tables 2, 3 and 4 suggest that the propensity score adjustment method for integrating the CCC dataset with the ESS had the highest standard of replication of the distribution of variables as in the original ESS dataset. It corrected for the under-selection of centrists and over-selection of left-wingers, especially among the stalwarts (Table 4). We were also aware of a left-wing bias in terms of the selection of demonstrations surveyed. Explicitly right-wing demonstrations were not surveyed, since those that occurred (of those that the CCC team were aware of) were small, consisting of no more than 300 demonstrators, or were billed as likely to attract violence and therefore unsuitable to survey for safety and ethical reasons. It is important to reiterate that our sample adjustments correct for our inability to survey small or violent demonstrations.

\section{Future Studies and Limitations}

Our propensity score adjustment method has broad applicability beyond the CCC project data with which we illustrate here. It might, for example, be used to combine conventional random survey samples with non-random internet survey responses (Passmore 2017). It also has applicability to observational studies in which the condition of randomization in experimental design is not fully met and to other rare populations not well captured by cross-national random surveys. Moreover, the method is highly 
applicable to other on-site studies, which face more pronounced problems of selection bias and response bias compared to protest surveys.

Critics might bemoan aggregation of protesters across issues, but our approach also at least partially corrects for this, and does no more disservice to aggregating protesters than existing cross-national surveys that measure participation in demonstrations.

Our work is an interesting first-step in assessing the extent to which different groups of protesters have become normalized. We would like to suggest ways to build further upon our study. At the moment, the results are based on analysis of data that is combined for the years 2008 to 2014. It would be interesting to present this as a longitudinal analysis. However, the number of protesters in the combined dataset for the ESS 2008-2014 is too small to take this step. The number of protesters in our dataset is just 351 across the aggregated years (92 in 2008, 57 in 2010, 81 in 2012 and 121 in 2014). To take this next important step in our research requires generating panel protest surveying over future 6year periods, and, again, creatively combining it with the ESS to ensure robust comparison of samples over time. This is certainly an interesting exercise to consider as more protest survey data becomes available over time. As it stands, we have assessed the extent to which different classes of protester have become normalized using a relatively robust methodology to integrate samples. In this regard, we make a significant methodological contribution to the literature, even though current data limitations make it impossible for us to assess this in a longitudinal fashion. 


\section{References}

Bailey, D.J.: Contending the Crisis: What Role for Extra-Parliamentary British Politics?

British Politics 9(1), 68-92 (2013)

Barnes, S.H. and Kaase, M. et al.: Political Action. London: Sage (1979)

Baker, R.J., Brick, M., Bates, N.A., Battaglia, M., Couper, M.P., Dever, J.A., Gile, K.J and Tourangeau, R.: Report of the AAPOR Task Force on Non-Probability Sampling. (2013) https://www.aapor.org/AAPOR_Main/media/MainSiteFiles/NPS_TF_Report Final_7_revised_FNL_6_22_13.pdf [accessed 16 August 2016].

Biggs, M.: Has Protest Increased Since the 1970s? How a Survey Question can Construct a Spurious Trend. British Journal of Sociology 66(1), 141-62 (2015)

Cochran, W.G.: The Effectiveness of Adjustment by Subclassification in Removing Bias in Observational Studies. Biometrics 20, 205-213 (1968)

Corrigall-Brown, C.: Patterns of Protest: Trajectories of Participation in Social Movements. Stanford University Press (2012)

Dalton, R.J.: Citizen Politics: Public Opinion and Political Parties in Advanced Industrial Democracies. Second Edition. Chatham House Publisher (1996)

Dalton, R.J.: Citizen Politics: Public Opinion and Political Parties in Advanced Industrial Democracies. Third Edition. Chatham House Publisher (2002)

Dalton, R.J: The Participation Gap: Social Status and Political Inequality. Oxford University Press (2017)

Downton, J. Jr and Wehr, P.: Persistent Pacifism: How Activist Commitment is Developed and Sustained. Journal of Peace Research 35(5), 531-550 (1998)

Elliott, M. R.: Combining Data from Probability and Non-Probability Samples Using PseudoWeights. Survey Practice 2(6), (2009) https://surveypractice.scholasticahq.com/article/2982-combining-data-from-probabilityand-non-probability-samples-using-pseudo-weights [accessed 09 July 2018].

Elliot, M.R. and Valliant, R.: Inference for Nonprobability Samples. Statistical Science 32(2), 249-264 (2017)

Etzoni, A.: Demonstration Democracy. Harwood Academic (1970)

Gallego, A.: Unequal Political Participation in Europe. International Journal of Sociology 37(4), 10-25 (2008)

Holmes, W.M.: Using Propensity Scores in Quasi-Experimental Designs. Thousand Oaks, Sage (2014)

Klandermans, B. and Oegema D.: Potentials, Networks, Motivations and Barriers: Steps Towards Participation in Social Movements. American Sociological Review 8(1), 519531 (1987)

Lee, S., and Valliant, R.: Estimation for Volunteer Panel Web Surveys using Propensity Score Adjustment and Calibration Adjustment. Sociological Methods and Research 37(3), 319-343 (2009)

Marsh, D.: Political Action in Europe and the USA. Palgrave Macmillan (1990) 
McAdam, D.: Recruitment to High-Risk Activism: The Case of Freedom Summer. American Journal of Sociology 92 (1), 64-90 (1986)

McAdam, D. and Paulsen, R.: Specifying the Relationship Between Social Ties and Activism. American Journal of Sociology 99, 640-667 (1993)

Meyer, D. and Tarrow, S.: The Social Movement Society: Contentious Politics for a New Century. Boulder, CO: Rowman and Littlefield (1998)

Norris, P.: Democratic Phoenix: Reinventing Political Activism, Cambridge: Cambridge University Press (2003)

Oberschall, A.: Social Conflict and Social Movements, Englewood Cliffs, N.J: Prentice-Hall (1973)

Passmore, P.: Consequences of Communicating Climate Science Online: The Effects on Young People's Reactions to Climate Science, unpublished $\mathrm{PhD}$ thesis, University of Exeter (2017)

Pattie, C., Seyd, P. and Whiteley, P.: Citizenship in Britain: Values, Participation and Democracy. Cambridge University Press (2004)

Rivers, D. and Bailey, D.: Inference from Matched Samples in the 2008 U.S. National Elections. Paper presented at the 64th Annual Conference of the American Association for Public Opinion Research, Hollywood, Florida, May (2009)

Rucht, D.: The Spread of Protest Politics. In: Dalton, R.J. and Klingemann, H. (eds) The Oxford Handbook of Political Behaviour, pp.708-723. Oxford University Press (2007)

Rosenbaum, P.R. and Rubin, D.B.: Reducing Bias in Observational Studies using SubClassification on the Propensity Score. Journal of the American Statistical Association 39, 516-524 (1984)

Rubin, D.B.: Using Multi-Variate Matched Sampling and Regression Adjustment to Control Bias in Observational Studies. Journal of the American Statistical Association 74, 318328 (1979)

Saunders, C.: Anti-politics in Action? Measurement Dilemmas in the Study of Unconventional Political Participation. Political Research Quarterly 67(3), 574-588 (2014)

Saunders, C., Grasso, M., Olcese, C., Rainsford, E. and Rootes, C.: Explaining Differential Protest Participation: Novices, Returners, Repeaters and Stalwarts. Mobilization 17(3), 263-80 (2012)

Snow, D.: A Primer on Social Movements. New York: W.W. Norton (2010)

Stryker, S.: Identity Salience and Role Performance. Journal of Marriage and the Family 4 (4), 558-564 (1968)

Torcal, M., Rodon, T. and Hierro, M.J.: Word on the Street: The Persistence of LeftistDominated protest in Europe. West European Politics 39(2), 326-350 (2016)

Van Aelst, P. \&Walgrave, S.: Who Is that (Wo)man in the Street? From the Normalisation of Protest to the Normalisation of the Protester. European Journal of Political Research 39(4), 461-486 (2001)

Van Stekelenberg, J., Walgrave, S., Klandermans, B. and Verhulst, J.: Contextualising Contestation: Framework, Design and Data. Mobilization: An International Quarterly 17(3), 249-262 (2012) 
Van Stekelenburg, J., and Klandermans, B.: The Social Psychology of Protest. Current Sociology 61(5-6), 886-905 (2013)

Verhulst, J. and Walgrave, S.: The First Time is the Hardest? A Cross-National and CrossIssue Comparison of First-Time Protest Participants. Political Behavior 31 (2), 455484 (2009)

Vráblíková, K.: How Context Matters? Mobilization, Political Opportunity Structures, and Nonelectoral Political Participation in Old and New Democracies. Comparative Political Studies 47(2), 203-229 (2014)

Walgrave, S.,Wouters, R. and Ketelaars, P.: Response Problems in the Protest Survey Design: Evidence from Fifty-One Protest Events in Seven Countries. Mobilization: An International Quarterly 21(1), 83-104 (2016)

Whiteley, P.: Political Participation in Britain: The Decline and Revival of Civic Culture. Palgrave MacMillan (2011) 
Figure 1: Schematic diagram of the analytical strategy

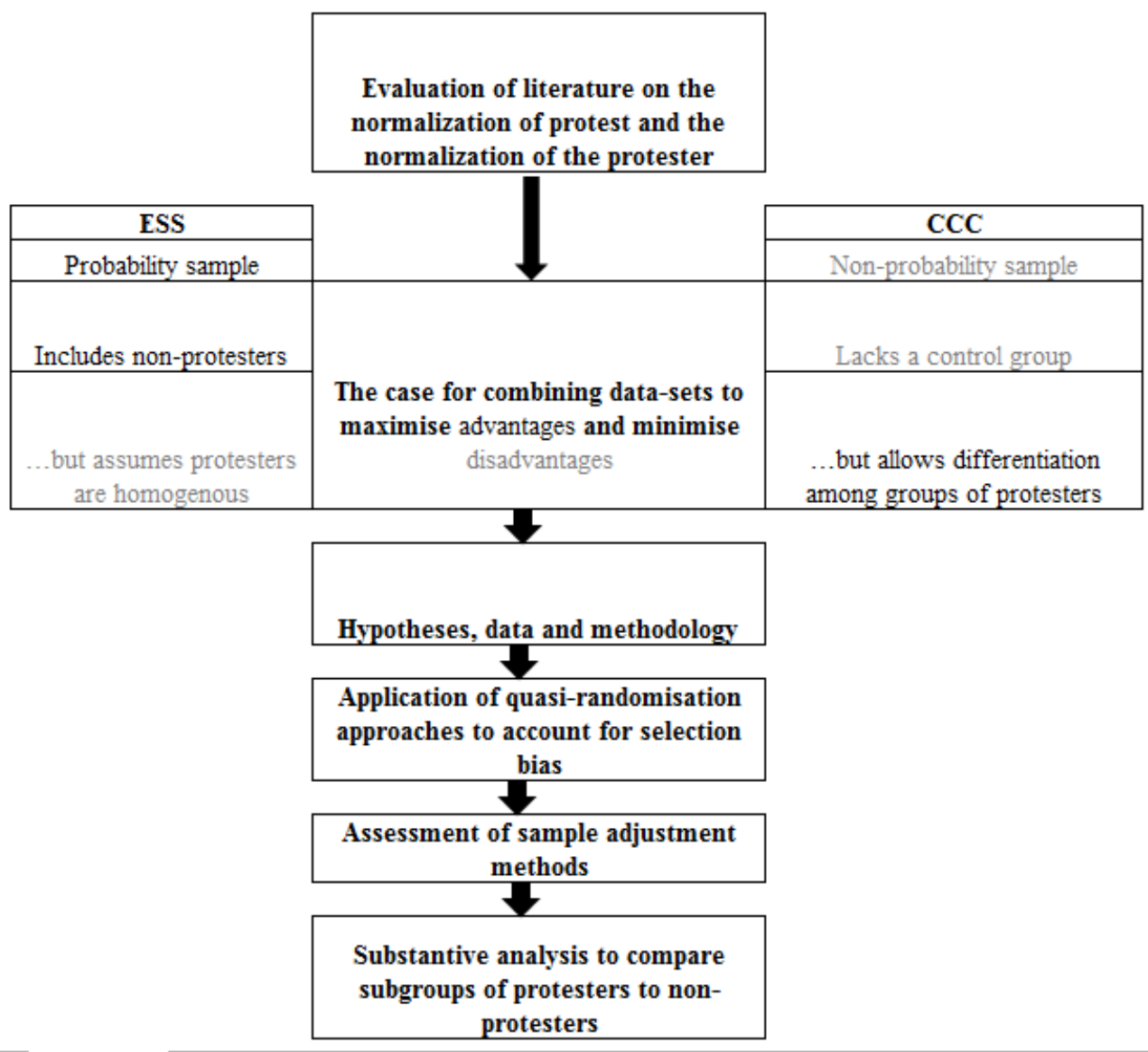


Table 1: UK demonstrations surveyed in CCC dataset

\begin{tabular}{llcc}
\hline Demonstration & \multicolumn{1}{c}{ Date } & $\begin{array}{c}\text { Sample Size } \\
\text { (n) }\end{array}$ & $\begin{array}{c}\text { Percentage of } \\
\text { Sample Size } \\
\text { (\%) }\end{array}$ \\
\hline National Climate March (2009) & 5 December 2009 & 227 & 9.0 \\
May Day Labour March & 1 May 2010 & 166 & 6.6 \\
Take Back Parliament & 15 May 2010 & 160 & 3.2 \\
Not to Hate Crime Vigil & 23 October 2010 & 344 & 13.6 \\
Unite Against Fascism & 6 November & 184 & 7.3 \\
Fund Our Future: Stop Education & 2010 & 146 & 5.8 \\
Cuts & 10 November & & 13.9 \\
National Climate March (2010) & 4 December 2010 & 351 & 3.8 \\
Second Student National & 9 December 2010 & 96 & 6.5 \\
Demonstration & 5 March 2011 & 165 & 7.8 \\
Million Women Rise & 26 March 2011 & 197 & 5.3 \\
TUC's March for the Alternative & 12 November & 135 & 7.3 \\
Occupy London & 2011 & & 7.0 \\
\hline London Pride Parade & 7 July 2012 & 185 & 100 \\
The Big If & & 177 & \\
\hline Total & & 2533 & \\
\hline
\end{tabular}


Table 2: Protesters and non-protesters combined, comparing proportions / means in the UK ESS dataset, with the combined ESS and CCC dataset after proportional weighting and propensity score adjustment

\begin{tabular}{|c|c|c|c|}
\hline Variable & $\begin{array}{c}\text { Original UK ESS } \\
\text { (with post-stratified } \\
\text { weights) }\end{array}$ & $\begin{array}{c}\text { Proportional } \\
\text { Weighting }\end{array}$ & $\begin{array}{l}\text { Propensity score } \\
\text { adjustment }\end{array}$ \\
\hline Protester $(\%)$ & 3.8 & 4.3 & 3.9 \\
\hline Auxiliary variables & & & \\
\hline $\begin{array}{l}\text { Voted in last election } \\
(\%)\end{array}$ & 63.0 & 64.5 & 64.4 \\
\hline Signed petition (\%) & 32.0 & 34.4 & 34.3 \\
\hline Worn badge $(\%)$ & 5.3 & 7.7 & 6.9 \\
\hline $\begin{array}{l}\text { Participated in boycott } \\
(\%)\end{array}$ & 19.3 & 21.6 & 21.0 \\
\hline \multicolumn{4}{|l|}{ Variables modelled } \\
\hline Is male $(\%)$ & 48.1 & 48.6 & 48.6 \\
\hline Has degree $(\%)$ & 15.0 & 17.9 & 16.3 \\
\hline Age (mean) & 46.5 & 46.6 & 46.6 \\
\hline Political interest (mean) & 2.4 & 2.5 & 2.5 \\
\hline \multicolumn{4}{|l|}{ Left-right } \\
\hline Don't know & 14.3 & 13.5 & 13.4 \\
\hline Extreme left & 3.7 & 4.4 & 3.9 \\
\hline Moderate left & 11.4 & 12.7 & 12.1 \\
\hline Centrist & 54.2 & 53.0 & 53.9 \\
\hline Moderate right & 14.0 & 13.9 & 14.1 \\
\hline Extreme right & 2.5 & 2.6 & 2.7 \\
\hline
\end{tabular}

Notes: There are no statistically significant differences between the samples on these key variables. 
Table 3: Protesters only in CCC and UK ESS, comparing design weighted datasets and the raw CCC dataset

\begin{tabular}{|c|c|c|c|c|}
\hline Variable & $\begin{array}{c}\text { Original UK } \\
\text { ESS (with } \\
\text { design weights) }\end{array}$ & $\begin{array}{l}\text { CCC } \\
\text { (raw) }\end{array}$ & $\begin{array}{l}\text { CCC (after } \\
\text { proportional } \\
\text { weighting) }\end{array}$ & $\begin{array}{c}\text { CCC (after } \\
\text { propensity score } \\
\text { adjustment) }\end{array}$ \\
\hline \multicolumn{5}{|l|}{$\begin{array}{l}\text { Auxiliary } \\
\text { variables }\end{array}$} \\
\hline $\begin{array}{l}\text { Voted in last } \\
\text { election }(\%)\end{array}$ & 79.0 & 81.2 & 80.3 & 80.7 \\
\hline $\begin{array}{l}\text { Signed petition } \\
(\%)\end{array}$ & 86.5 & 88.6 & 88.7 & 86.6 \\
\hline $\begin{array}{l}\text { Worn badge } \\
(\%)\end{array}$ & 34.8 & 62.2 & 62.1 & 40.2 \\
\hline $\begin{array}{l}\text { Participated in } \\
\text { boycott }(\%)\end{array}$ & 53.4 & 67.7 & 67.1 & 53.7 \\
\hline \multicolumn{5}{|l|}{$\begin{array}{l}\text { Variables } \\
\text { modelled }\end{array}$} \\
\hline Is male $(\%)$ & 46.3 & 49.9 & 46.0 & 49.5 \\
\hline Has degree $(\%)$ & 35.7 & 82.5 & 82.5 & 38.1 \\
\hline Age (mean) & 46.4 & 43.1 & 41.2 & 47.2 \\
\hline $\begin{array}{l}\text { Political } \\
\text { interest (mean) }\end{array}$ & 3.1 & 3.4 & 3.4 & 3.1 \\
\hline \multicolumn{5}{|l|}{ Left-right } \\
\hline Don't know & 3.4 & 7.7 & 7.8 & 4.0 \\
\hline Extreme left & 9.9 & 23.4 & 23.2 & 10.1 \\
\hline Moderate left & 27.8 & 45.8 & 45.3 & 29.4 \\
\hline Centrist & 45.6 & 20.4 & 20.8 & 44.9 \\
\hline Moderate right & 10.8 & 2.5 & 2.4 & 9.4 \\
\hline Extreme right & 2.4 & 0.4 & 0.4 & 2.2 \\
\hline
\end{tabular}

Note: There are no statistically significant differences between the UK ESS (with design weights) and the CCC under the propensity score adjustment approach. 
Table 4. Descriptive statistics on the raw unadjusted combined CCC and ESS dataset, proportionally weighted dataset and propensity score adjustment dataset $(n=11,404)$

\begin{tabular}{|c|c|c|c|c|c|c|}
\hline Sample & $\begin{array}{l}\text { Variable } \\
\text { (sample size } \\
\text { n) }\end{array}$ & $\begin{array}{l}\text { Non- } \\
\text { protester } \\
\mathbf{n}=\mathbf{8 , 8 7 1}\end{array}$ & $\begin{array}{l}\text { Novice } \\
\mathrm{n}=182\end{array}$ & $\begin{array}{l}\text { Middle } \\
\mathrm{n}=\mathbf{2 , 0 0 2}\end{array}$ & $\begin{array}{l}\text { Stalwart } \\
n=349\end{array}$ & $\begin{array}{l}\text { Adjusted } \\
\text { F (p) }\end{array}$ \\
\hline \multirow{11}{*}{$\begin{array}{l}\text { Unadjusted } \\
\text { Combined } \\
\text { Dataset }\end{array}$} & Age (mean) & 51 & 37.1 & 43.4 & 44.6 & $* * *$ \\
\hline & $\begin{array}{l}\text { Has degree } \\
(\%)\end{array}$ & 14.9 & 74.7 & 83.5 & 80.0 & $* * *$ \\
\hline & Male (\%) & 44.0 & 47.8 & 49.2 & 55.3 & $* * *$ \\
\hline & $\begin{array}{l}\text { Political } \\
\text { interest } \\
\text { (mean) }\end{array}$ & 2.5 & 2.9 & 3.4 & 3.5 & $* * *$ \\
\hline & Left-right & & & & & \multirow{7}{*}{$* * *$} \\
\hline & Don't know & 13.5 & 22.0 & 6.7 & 5.7 & \\
\hline & Extreme left & 3.7 & 10.4 & 20.0 & 49.6 & \\
\hline & $\begin{array}{r}\text { Moderate } \\
\text { left }\end{array}$ & 11.4 & 32.4 & 49.0 & 34.4 & \\
\hline & Centrist & 54.1 & 29.1 & 21.8 & 7.7 & \\
\hline & $\begin{array}{r}\text { Moderate } \\
\text { right }\end{array}$ & 14.7 & 5.5 & 2.2 & 2.6 & \\
\hline & $\begin{array}{r}\text { Extreme } \\
\text { right } \\
\end{array}$ & 3.1 & 0.6 & 0.4 & 0.0 & \\
\hline \multirow{11}{*}{$\begin{array}{l}\text { Proportional } \\
\text { Weighting } \\
\text { Approach }\end{array}$} & Age (mean) & 46.9 & 35.5 & 41.5 & 42.7 & $* * *$ \\
\hline & $\begin{array}{l}\text { Has degree } \\
(\%)\end{array}$ & 15.3 & 74.8 & 83.5 & 81.1 & $* * *$ \\
\hline & Male (\%) & 48.4 & 51.7 & 53.4 & 59.2 & $* * *$ \\
\hline & $\begin{array}{l}\text { Political } \\
\text { interest } \\
\text { (mean) }\end{array}$ & 2.5 & 3.0 & 3.4 & 3.5 & $* * *$ \\
\hline & Left-right & & & & & \multirow{7}{*}{$* * *$} \\
\hline & Don't know & 13.7 & 22.1 & 6.8 & 5.9 & \\
\hline & Extreme left & 3.5 & 10.8 & 19.6 & 50.6 & \\
\hline & $\begin{array}{r}\text { Moderate } \\
\text { left }\end{array}$ & 11.4 & 32.2 & 48.7 & 33.4 & \\
\hline & Centrist & 54.3 & 29.1 & 22.3 & 7.7 & \\
\hline & $\begin{array}{r}\text { Moderate } \\
\text { right }\end{array}$ & 14.3 & 5.3 & 2.2 & 2.3 & \\
\hline & $\begin{array}{r}\text { Extreme } \\
\text { right }\end{array}$ & 2.7 & 0.6 & 0.4 & 0.0 & \\
\hline $\begin{array}{l}\text { Propensity } \\
\text { score } \\
\text { adjustment } \\
\text { Approach }\end{array}$ & Age (mean) & 46.7 & 40.9 & 45.6 & 48.9 & n.s \\
\hline
\end{tabular}




\begin{tabular}{|c|c|c|c|c|c|}
\hline $\begin{array}{l}\text { Has degree } \\
(\%)\end{array}$ & 15.4 & 32.5 & 38.7 & 45.5 & $* * *$ \\
\hline Male (\%) & 48.4 & 47.4 & 54.7 & 58.0 & n.s \\
\hline $\begin{array}{l}\text { Political } \\
\text { interest } \\
\text { (mean) }\end{array}$ & 2.5 & 2.7 & 3.2 & 3.1 & $* * *$ \\
\hline Left-right & & & & & \\
\hline Don't know & 13.7 & 11.1 & 3.3 & 3.2 & \\
\hline Extreme left & 3.6 & 9.4 & 8.4 & 32.1 & \\
\hline $\begin{array}{r}\text { Moderate } \\
\text { left }\end{array}$ & 11.4 & 18.8 & 31.3 & 25.0 & $* * *$ \\
\hline Centrist & 54.3 & 47.0 & 45.6 & 33.3 & \\
\hline $\begin{array}{r}\text { Moderate } \\
\text { right }\end{array}$ & 14.3 & 12.6 & 9.2 & 6.5 & \\
\hline $\begin{array}{r}\text { Extreme } \\
\text { right }\end{array}$ & 2.7 & 1.1 & 2.0 & 0.0 & \\
\hline
\end{tabular}

Note: The adjusted $\mathrm{F}$ is an adjusted Chi2, except for the scale variable (age and political interest) for which the adjusted ANOVA scores are derived from a regression (age and political interest as dependent variables and sub-group as the independent variable) $* * * \mathrm{p}$ value $<0.001, * *$ p-value $<0.01,{ }^{*}$-value $<0.05$.

Table 5: Multinomial logistic regression on the raw unadjusted combined CCC and ESS dataset, proportionally weighted dataset and propensity score adjustment dataset $(n=11,404)$

\begin{tabular}{lccc}
\hline & Raw & $\begin{array}{c}\text { Proportionally } \\
\text { weighted }\end{array}$ & $\begin{array}{c}\text { Propensity } \\
\text { score } \\
\text { adjustment }\end{array}$ \\
\hline $\begin{array}{l}\text { Non-protesters (base category } \\
\text { Novices (n=182) }\end{array}$ & & $871)$ & \\
Age & $-0.04 * * *$ & $-0.04 * * *$ & -0.02 \\
Political interest & $0.40 * * *$ & $0.47 * * *$ & 0.28 \\
Extreme left & 0.06 & 0.15 & $0.99 *$ \\
Moderate left & -0.31 & -0.30 & 0.40 \\
Centrist & $-1.51 * * *$ & $-1.54 * * *$ & -0.06 \\
Moderate right & $-1.96 * * *$ & $-1.99 * * *$ & -0.05 \\
Extreme right & $-2.21 *$ & $-2.36 *$ & -0.72 \\
Has degree & $2.57 * * *$ & $2.58^{* * *}$ & $0.76 * *$ \\
Is male & -0.27 & -0.08 & 0.14 \\
Constant & $-3.00 * * *$ & $-5.80 * * *$ & $-5.72 * * *$ \\
\hline
\end{tabular}




\begin{tabular}{|c|c|c|c|}
\hline \multicolumn{4}{|l|}{$\begin{array}{l}\text { Middle } \\
(n=2,002)\end{array}$} \\
\hline Age & $-0.02 * * *$ & $-0.01 * * *$ & 0.00 \\
\hline \multicolumn{3}{|l|}{ LR } & $0.80 * * *$ \\
\hline Extreme left & $1.33 * * *$ & $1.34 * * *$ & $1.46^{* * *}$ \\
\hline Moderate left & $0.80 * * *$ & $0.72 * * *$ & $1.53 * * *$ \\
\hline Centrist & $-0.98 * * *$ & $-1.08 * * *$ & $0.69 * * *$ \\
\hline Moderate right & $-2.22 * * *$ & $-2.28 * * *$ & 0.20 \\
\hline Extreme right & $-2.10 * * *$ & $-2.29 * * *$ & 0.50 \\
\hline Has degree & $2.81 * * *$ & $2.82 * * *$ & $0.78 * * *$ \\
\hline Is male & -0.20 & -0.03 & -0.03 \\
\hline Constant & $-4.05 * * *$ & $-6.65 * * *$ & $-6.45 * * *$ \\
\hline \multicolumn{4}{|l|}{$\begin{array}{l}\text { Stalwarts } \\
(n=349)\end{array}$} \\
\hline Age & $-0.01 * * *$ & $-0.01 * * *$ & 0.01 \\
\hline \multicolumn{4}{|l|}{ LR } \\
\hline Extreme left & $2.38 * * *$ & $2.35 * * *$ & $2.92 * * *$ \\
\hline Moderate left & $0.60 *$ & 0.42 & $1.36 * *$ \\
\hline Centrist & $-1.90 * * *$ & $-2.08 * * *$ & 0.39 \\
\hline Moderate right & $-1.93 * * *$ & $-2.16 * * *$ & -0.14 \\
\hline Extreme right & -15.71 & $-19.81 * * *$ & $-12.08 * * *$ \\
\hline Has degree & $2.71 * * *$ & $2.74 * * *$ & $1.20 * * *$ \\
\hline Is male & $-0.49 * * *$ & $-0.25^{*}$ & -0.21 \\
\hline Constant & $-5.53 * * *$ & $-8.63 * * *$ & $-8.72 * * *$ \\
\hline $\operatorname{Adj} F$ & & $359.73 * * *$ & $468.67 * * *$ \\
\hline Pseudo R2 & 0.41 & & \\
\hline
\end{tabular}




\section{Appendix}

Table A1: Variable coding

\begin{tabular}{|c|c|c|}
\hline Variable name & Variable description & Coding \\
\hline demonstrator & $\begin{array}{l}\text { Has participated in demo in } \\
\text { past } 12 \text { months (ESS data } \\
\text { only) }\end{array}$ & $\begin{array}{l}1=\text { yes } \\
0=\text { no } \\
99=\text { no answer }\end{array}$ \\
\hline Age & Calculated age of respondent & $\begin{array}{l}\text { N/A (dropped those }<15 \text { and } \\
>105 \text { years of age) }\end{array}$ \\
\hline DV & $\begin{array}{l}\text { Protest participation (non- } \\
\text { protesters from ESS, } \\
\text { protesters from CCC) }\end{array}$ & $\begin{array}{l}0=\text { non-protester } \\
1=\text { novice } \\
2=\text { middle } \\
3=\text { stalwart } \\
4=\text { ESS protester } \\
99=\text { missing }\end{array}$ \\
\hline polint & Political interest & $\begin{array}{l}1=\text { not at all (includes don't } \\
\text { know) } \\
2=\text { not very } \\
3=\text { quite } \\
4=\text { very much } \\
99=\text { no answer }\end{array}$ \\
\hline demoever & $\begin{array}{l}\text { Participation in } \\
\text { demonstrations ever (CCC } \\
\text { only) }\end{array}$ & $\begin{array}{l}1=\text { Not before } \\
2=1-5 \text { times } \\
3=6 \text { or more times } \\
99=\text { missing }\end{array}$ \\
\hline demo12 & $\begin{array}{l}\text { Participation in } \\
\text { demonstrations in the past } \\
12 \text { months (CCC only) }\end{array}$ & $\begin{array}{l}1=\text { Not before } \\
2=1-5 \text { times } \\
3=6 \text { or more times } \\
99=\text { missing }\end{array}$ \\
\hline parlia & Trust: National parliament & $\begin{array}{l}0=\text { don't know } \\
1=\text { not at all } \\
2=\text { not very } \\
3=\text { somewhat } \\
4=\text { quite } \\
5=\text { very much } \\
99=\text { missing }\end{array}$ \\
\hline voted & Voted in last elections & $\begin{array}{l}0=\text { no } \\
1=\text { yes }\end{array}$ \\
\hline politician & $\begin{array}{l}\text { Contacted a politician (past } \\
12 \text { months) }\end{array}$ & $\begin{array}{l}0=\text { no } \\
1=\text { yes }\end{array}$ \\
\hline badge & $\begin{array}{l}\text { Worn a badge / sticker (past } \\
12 \text { months) }\end{array}$ & $\begin{array}{l}0=\text { no } \\
1=\text { yes }\end{array}$ \\
\hline petition & $\begin{array}{l}\text { Signed a petition (past } 12 \\
\text { months) }\end{array}$ & $\begin{array}{l}0=\text { no } \\
1=\text { yes }\end{array}$ \\
\hline boycott & $\begin{array}{l}\text { Boycotted products (past } 12 \\
\text { months) }\end{array}$ & $\begin{array}{l}0=\text { no } \\
1=\text { yes }\end{array}$ \\
\hline satisdem & Satisfaction with democracy & 0-10 scale recoded: \\
\hline
\end{tabular}




\begin{tabular}{|l|l|l|}
\hline & & $0=$ don't know \\
& & $1=0$ THRU 1 (not at all) \\
& & 2= 2 THRU 3 (not very) \\
& & 3=4 THRU 6 (somewhat) \\
& & 4 7 THRU 8 (quite) \\
& $5=9$ THRU (very much) \\
\hline gender & Gender & $1=$ male \\
& & $2=$ female \\
\hline $\operatorname{lr}$ & Left-right self-placement & $0=10$ scale recoded: \\
& & $0=$ don't know \\
& & $1=0$ THRU 1 (extreme left) \\
& & $2=2$ THRU 3 (moderate \\
& & left) \\
& & $3=4$ THRU 6 (centrist) \\
& & $4=7$ THRU 8 (moderate \\
& & right) \\
& & $5=9$ THRU 10 (extreme \\
& & right) \\
\hline degree & Has a university degree & $0=$ no \\
\hline
\end{tabular}

Table A2: F-statistics for testing differences in effect sizes under the propensity score adjustment method: novices to middle group, middle group to stalwarts, novices to stalwarts

\begin{tabular}{|c|c|c|c|}
\hline & $\begin{array}{l}\text { Novices to } \\
\text { middle group }\end{array}$ & $\begin{array}{l}\text { Middle group to } \\
\text { stalwarts }\end{array}$ & $\begin{array}{l}\text { Novices to } \\
\text { stalwarts }\end{array}$ \\
\hline Age & 2.75 & 1.46 & 1.9 \\
\hline Political Interest & $33.82 * * *$ & $34.19 * * *$ & 2.72 \\
\hline
\end{tabular}




\begin{tabular}{|l|r|r|r|} 
Extreme left & $28.02 * * *$ & $49.16^{* * *}$ & $28.04 * * *$ \\
Moderate left & $32.89^{* * *}$ & $36.39^{* * *}$ & $5.32 * *$ \\
Centrist & $6.63 * *$ & $6.76^{* *}$ & 0.25 \\
Moderate right & 0.19 & 0.23 & 0.04 \\
Extreme right & 0.6 & $338.46^{* * *}$ & $332.2 * * *$ \\
Has Degree & $26.13^{* * *}$ & $32.38^{* * *}$ & $13.91 * * *$ \\
Is Male & 0.14 & 0.34 & 0.43 \\
\hline \multicolumn{2}{|l}{}
\end{tabular}

Table A3: Multinomial regression on the dependent variable for protesters only (novices, the middle group or stalwarts) with demonstration effects included

\begin{tabular}{|c|c|c|c|}
\hline & Raw & $\begin{array}{c}\text { Proportionally } \\
\text { weighted }\end{array}$ & $\begin{array}{c}\text { Propensity score } \\
\text { adjustment }\end{array}$ \\
\hline \multicolumn{4}{|l|}{ Novices (base category) } \\
\hline \multicolumn{4}{|l|}{ Middle group } \\
\hline Age & $0.02 * * *$ & $0.02 * *$ & $0.03 *$ \\
\hline Political interest & $0.50 * * *$ & $0.51 * * *$ & $0.52 * *$ \\
\hline \multicolumn{4}{|c|}{ Left-right self-placement (base = don’t know) } \\
\hline Extreme left & $1.12 * *$ & $1.04 * *$ & $0.23 *$ \\
\hline Moderate left & $1.15^{* * *}$ & $1.13 * * *$ & 1.19 \\
\hline Centrist & $0.60 *$ & $0.59 *$ & 0.69 \\
\hline Moderate right & 0.09 & 0.13 & 0.68 \\
\hline Extreme right & 0.24 & 0.29 & 1.37 \\
\hline Has degree & 0.33 & 0.35 & 0.27 \\
\hline Is male & -0.00 & -0.01 & -0.37 \\
\hline \multicolumn{4}{|l|}{ Demo effects (base $=$ The Big If 2013) } \\
\hline National Climate March 2009 & 0.13 & 0.06 & 0.59 \\
\hline May Day 2010 & 1.07 & $1.12 *$ & $2.65 * * *$ \\
\hline Take Back Parliament 2010 & 0.59 & $0.66^{*}$ & 0.21 \\
\hline No to Hate Crime Vigil 2010 & 0.31 & 0.31 & 0.91 \\
\hline Unite Against Fascism 2010 & $1.35 *$ & $1.29 *$ & 0.64 \\
\hline Fund Our Future 2010 & 0.08 & 0.09 & 0.91 \\
\hline Climate March 2010 & $3.01 * * *$ & $2.98 * * *$ & 1.31 \\
\hline $2^{\text {nd }}$ National Student demo 2010 & $1.36^{*}$ & $1.39 *$ & $2.21 *$ \\
\hline
\end{tabular}


Million Women Rise $2010 \quad 1.42 \quad 1.42 \quad 1.18$

$\begin{array}{llll}\text { TUC March for Alternative } 2010 & 0.26 & 0.31 & 0.31\end{array}$

$\begin{array}{llll}\text { Occupy } 2011 & 0.51 & 0.59 & 1.19\end{array}$

London Pride Parade $2012 \quad 0.33 \quad 0.34 \quad 0.74$

Constant

$-1.75 * * * \quad-1.77 * \quad-1.64$

Stalwarts

$\begin{array}{llll}\text { Age } & 0.02 * * & 0.02 * * & 0.03\end{array}$

$\begin{array}{llll}\text { Political interest } & 0.34 * * & 0.39 * * & 0.14\end{array}$

Left-right self-placement (base = don't know)

$\begin{array}{rccc}\text { Extreme left } & 1.82 * * * & 1.78 * * * & 1.11 \\ \text { Moderate left } & 0.92 * * & 0.87 * * & 0.84 \\ \text { Centrist } & -0.25 & -0.29 * & 0.20 \\ \text { Moderate right } & -0.51 & 0.43 * & 1.27 \\ \text { Extreme right } & -12.23 & -12.40^{* * *} & -12.32 * * * \\ & 0.27 & 0.35 & 0.42 \\ & -2.20 & -0.01 & -0.92 *\end{array}$

Has degree

Is male

$-2.20$

$-0.92 *$

Demo effects (base $=$ The Big If 2013)

National Climate March 2009

May Day 2010

0.36

0.37

1.91

Take Back Parliament 2010

$2.54 * * *$

$2.68 * * *$

$5.05 * * *$

No to Hate Crime Vigil 2010

$1.12 *$

$1.24 *$

$-0.20$

Unite Against Fascism 2010

0.28

0.23

1.36

Fund Our Future 2010

$3.34 * * *$

$3.22 * * *$

$2.72 * *$

$-0.72$

$-0.70$

$-0.90$

Climate March 2010

$4.15^{* * *}$

$4.16^{* * * *}$

$2.72 *$

$2^{\text {nd }}$ National Student Demo 2010

$2.42 * *$

$2.48 * * *$

$2.73 *$

Million Women Rise 2010

$2.10 * *$

$2.09 * * *$

$2.94 *$

TUC March for Alternative 2010

0.56

0.57

0.59

Occupy 2011

$1.81 * *$

$1.91 * * *$

$2.18^{* *}$

London Pride Parade 2012

Constant

0.54

0.57

$-0.6$

$-3.15^{*}$

R2

0.14

$* * * \mathrm{p}$-value $<0.001, * * \mathrm{p}$-value $<0.01, * \mathrm{p}$-value $<0.05$

Notes: This table is illustrative of demonstration effects in the distribution of novices, the middle group and stalwarts for protesters only. 